\title{
La narrativa indigenista en Argentina. Una doble denuncia
}

\author{
María del Carmen NiCOLÁs ALBA \\ University of Arizona, Department of Spanish and Portuguese \\ mnicolasalba@email.arizona.edu
}

\begin{abstract}
RESUMEN
Desde tiempos de José Carlos Mariátegui, la crítica literaria indigenista viene articulando un discurso etnocentrista cuyo eje de producción se sitúa en Perú y los países vecinos, pero rara vez se ha mencionado una obra argentina que trate sobre las desigualdades que sufren los indígenas de ese país. Ni siquiera la academia argentina ha analizado ninguna novela desde la óptica indigenista.

En un país cuyos gobiernos, desde el siglo XIX, han tratado de borrar cualquier traza de sangre indígena en su población, ya sea mediante la asimilación, exterminio o invisibilidad, y cuyas zonas de mayor asentamiento indígena se encuentran lejos del hegemónico Buenos Aires, las narraciones de problemas sociales ajenos quedaban encajonadas en el recóndito mundo de la literatura regional.

Sin embargo, durante los años de eclosión del movimiento indigenista, escritores argentinos se hicieron eco de los sufrimientos y demandas de sus compatriotas indígenas por medio de novelas que sobrepasaron el peyorativo epíteto regionalista y que incomprensiblemente, han sido olvidadas.

En este artículo, que forma parte de un estudio más amplio, se aborda el silencio crítico, se contextualiza la producción indigenista de la época y se analizan brevemente algunas de las obras.
\end{abstract}

Palabras clave: indigenismo, Argentina, Fausto Burgos.

\section{Indigenista narrative in Argentina. A double condemnation}

\begin{abstract}
From the times of José Carlos Mariátegui, Indigenismo literary criticism has been articulating an ethnocentric discourse which production core is located in Peru and surrounding countries. However, rarely an Argentinian work that deals about inequalities of indigenous peoples has been mentioned, not even the Argentinian academia itself.

In a country whose governments, from mid- $19^{\text {th }} \mathrm{c}$ have been trying to erase any trace of indigenous blood in its population, by means of assimilation, extermination or invisibility, and whose major indigenous areas are placed far from the hegemonic Buenos Aires, social novels were pushed aside in the world of regional literature.
\end{abstract}


However, during the blooming of the Indigenista movement, Argentinian writers echoed the sufferings and demands of their indigenous fellows by means of novels that overpassed the regionalist pejorative epithet and, beyond all understanding, have been forgotten.

In this article, that is part of a major work, the silence from the critics is approached, the Indigenista production is contextualized and some of their works are briefly analyzed.

Key words: Indigenismo, Argentina, Fausto Burgos.

SUMARIO: 1 . El silencio de la crítica. 2. La narrativa indigenista argentina como producción regional. 3. Obras indigenistas en Argentina.

\section{El silencio de la crítica}

Aunque la mayor parte de los críticos coinciden en situar el auge de la literatura indigenista en la segunda década del siglo XX, solo Cornejo Polar ha señalado la naturaleza cíclica y continuada de este movimiento ${ }^{1}$, conclusión ya principiada por Kristal $^{2}$ e insinuada por Alberto Sánchez, Cometta Manzoni, Saintoul, Grossman, Prieto, Alegría y Meléndez, al mencionar - o analizar - , en sus respectivos estudios sobre las literaturas relacionadas con el indígena americano, un largo listado de antecedentes literarios cuyo primer lugar ocupa, indudablemente, Bartolomé de las Casas.

A lo largo de los siglos inmediatamente posteriores a la Conquista y previos a las independencias, el tema indígena ocupa las páginas de ficción europeas desde, entre otras, la rousseauniana perspectiva del "buen salvaje" que inició Michel de Montaigne con su ensayo Des cannibales y al que siguieron multitud de autores ${ }^{3}$ hasta culminar con Atala (1801) de Chauteaubriand, verdadero estímulo del indianismo, que Cornejo Polar ha calificado como "indigenismo romántico". Con este epígrafe, el movimiento queda adscrito a la estética del Romanticismo, siendo la mejor vía para comprender su idiosincrasia, además de las características comunes de "exotismo, su ausencia de vigor reivindicativo..., su incomprensión de los niveles básicos, económico-sociales, del problema indígena” (1980:36). Concha

1 “Aunque en sentido estricto el indigenismo es un movimiento que surge y se consolidad a partir de la década de los 20 , en una acepción más amplia puede ratreársele en lo que toca a sus orígenes - desde los tiempos inmediatamente posteriores a la Conquista" (Cornejo Polar 1980:33).

2 "Se debe reconsiderar la visión general que ubica el origen del indigenismo en toda la región andina con la obra Aves sin nido (1889) de Clorinda Matto de Turner. En el Perú existió una continua producción indigenista literaria desde la década del 40 del siglo pasado [siglo XIX] hasta la década del 80 del mismo siglo" (Kristal 1991:204).

${ }^{3}$ Entre otros, Voltaire con Alzire, Candide y L'ingénu; Jean-François Marmontel con Les incas; Françoise de Graffigny con Lettres d'une Péruvienne; por supuesto Rousseau con su famoso ensayo Discours sur l'origine et les fondements de l'inégalité parmi les hommes (1755); y Jacques-Henri Bernardin de Saint Pierre con Paul et Virginie. 
Meléndez, la autora que ha analizado la novela indianista con mayor profundidad, afirma que en ella, "los indios y sus tradiciones están presentados con simpatía" (1961:13). Rodríguez-Luis señala al indio y no al indígena como el objeto de la literatura indianista mientras que René Prieto, además de los rasgos comunes a la literatura romántica americana establecidos por Meléndez, añade, para diferenciarlo del indigenismo, la ausencia de protesta social.

La definición de Cornejo Polar resulta clarividente para diferenciar el subgénero romántico del movimiento estético y denunciatorio que se desarrollaría desde finales del siglo XIX hasta mediados del siglo XX. Aunque los límites entre uno y otro no son fáciles de discernir, la trascendencia de su disparidad alcanza objetivos sociales de los que sus autores son plenamente conscientes. La identificación de indianismo con indigenismo, como muchos críticos literarios han realizado ${ }^{4}$, produce incompatibilidades con el mismo objeto de la producción indigenista, a pesar de que ya en 1934 Concha Meléndez estableció sus diferencias en su estudio La novela indianista en Hispanoamérica, y posteriormente estas fueron siendo actualizadas sucesivamente por Alfredo Yépez Miranda (1935), Aída Cometta Manzoni (1960) y finalmente por Antonio Cornejo Polar y Tomás Escajadillo. Este último aporta una herramienta simple pero útil para discernirlos: considerar indianista todo lo que no sea indigenista y para ello define los requisitos que ha de tener toda novela indigenista, que veremos más adelante.

La multiplicidad de rasgos que las autoridades en materia de indigenismo han señalado, en ocasiones contradictorios, dificultan la tarea del investigador a la hora de catalogar una obra como indianista o indigenista. A este respecto, resulta significativa la crítica que realiza Efraín Kristal sobre la clasificación tipológica de las novelas indigenistas que hasta la fecha habían desarrollado los críticos, sin recordar que una de las primeras críticas literarias sobre el indigenismo la realizó en 1890 Emilio Gutiérrez de Quintanilla, censurando otras obras anteriores, de la misma manera que durante el siglo XX se fueron añadiendo y descartando obras literarias según el criterio del momento (1991:18-21). Apela Kristal al "efecto del realismo" acuñado por Pierre Bourdieu, por el que la realidad se ve deformada por las diferentes concepciones sincrónicas. Además, subraya Kristal que no es posible clasificar una obra literaria por su posición ideológica o antropológica ya que se trata de planos distintos.

Para seguir una catalogación diacrónica, señalaremos las características que estos críticos han otorgado al indigenismo. Así, Cometta Manzoni antepone el elemento reivindicativo sobre el estético ${ }^{5}$; Kristal reafirma su teoría urbana,

${ }^{4}$ Sirva de ejemplo el capítulo dedicado al indigenismo de Ricardo Gullón en su obra Direcciones del modernismo.

5 Afirma que la novela indigenista "responde a los reclamos urgentes de su momento histórico", "es una tendencia revolucionaria" que "no siempre es estética", es "un 
asociando indigenismo con política ${ }^{6}$; Cornejo Polar toma en cuenta consideraciones teóricas, el referente, el componente lírico y su carácter heterogéneo. Según el crítico peruano, en la novela indigenista subyacen elementos ajenos al orden occidental de la novela y por eso, la primacía no se centra en el individuo; el autor toma en cuenta el referente y se adecúa a las formas literarias indígenas, además de añadir elementos míticos procesados con recursos épicos en lugar de novelescos. Además, Cornejo Polar remite al compartido rasgo de denuncia, y añade que la novela indigenista es novelable desde fuera, existe una ruptura de la continuidad temporal por la que el pasado glorioso ya no resulta atractivo ni su continuidad es la solución a los problemas de los indígenas; el autor indigenista prefiere la elegía y la tragedia a la utopía y finalmente descarta cualquier solución real política por parte de los indigenistas. Tomás Escajadillo distingue dos presencias del tema indígena (indianismo modernista e indianismo romántico) y dos momentos del indigenismo (indigenismo ortodoxo y neoindigenismo), e indica los requisitos que debe cumplir una novela indigenista, a saber: sentimiento de reivindicación social, superación de lastres pasados y proximidad al mundo novelado.

Es necesario, sin embargo, tener en cuenta, que tanto Antonio Cornejo Polar como Tomás Escajadillo y Efraín Kristal son autores peruanos, y sus estudios se restringen, si no solo a Perú (o a los países donde supuestamente siguen existiendo indígenas), a la prefigurada área andina ${ }^{7}$. La adecuación geográfica de la denominada región andina ya fue señalada por Ángel Rama, que incluyó todas las zonas del Inkario, desde Colombia hasta Argentina (1982:124), mientras que Poderti reconoce una zona específica "de fuerte incidencia en la cultura incásica" (2000:16). Esta apreciación implica una adecuación de los presupuestos teóricos de dichos críticos a la realidad literaria argentina.

Aun así, muchos de los planteamientos teóricos propuestos por los mencionados críticos son válidos desde un punto de vista pragmático y evolutivo, pues las raíces indianistas señaladas se localizan en toda Latinoamérica y en particular, en la parte más austral de Sudamérica por razones históricas relacionadas con las

movimiento de denuncia para promover una reacción violenta" que "describe la opresión, la esclavitud y el dolor indio" (1960:12).

6 "El indigenismo es un fenómeno literario urbano que expresa los puntos de vista que tienen los ciudadanos respecto al indio", "No se relacionaba con la cultura indígena directamente", "Participa en la formación de posiciones políticas respecto al indio" y es un "vehículo literario para los activistas políticos excluidos de la arena política" (1991:203).

${ }^{7}$ Quisiéramos subrayar "prefigurada", ya que, en general, los críticos circunscriben esta zona a Perú, Bolivia y Ecuador, obviando, si no olvidando, que los Andes recorren todos los países de Sudamérica occidental. Si asumimos que con el adjetivo "andino" pretenden identificar, en términos geográficos, el altiplano, y en términos históricos, el antiguo Tawantinsuyo, también en este caso se observa una indiferencia destacable en lo que respecta al norte de Chile y al noroeste de Argentina (el antiguo Collasuyo incaico). 
independencias. El rigor histórico obligaría a impedir la definición de indigenista a dichas novelas por el origen político y localista de dicho vocablo, realidades y evoluciones con pocos puntos en común con las argentinas. Efectivamente, el movimiento indigenista peruano, antioligárquico y marxista, aceleró la producción artística relacionada, o más bien, intensificó sus ecos en una sociedad claramente estratificada y dividida en función de las razas y donde el contacto interracial y la influencia mutua eran una constante. Por tanto, la revalorización de la cultura indígena, que comenzó en el siglo anterior con la reivindicación del pasado incaico, aderezada con los postulados marxistas que llegó a su clímax con Mariátegui, debía desembocar necesariamente en una reclamación de los derechos indígenas. La misma situación se puede aplicar a la novela indigenista en México en relación a la Revolución, aunque esa producción haya surgido por cauces muy diferentes a la peruana.

Sin embargo, en Argentina, aunque es obvio que la repercusión del movimiento indigenista arribó a las regiones andinas del noroeste, y que la situación social podía asemejarse a la de los países vecinos, la realidad política (y literaria) del conjunto del país dificultaba la trascendencia del indigenismo, una corriente más bien exótica ${ }^{8}$ en un país en el que los indígenas representan menos del $5 \%$. Aunque es evidente que autores como Fausto Burgos o Manuel J. Castilla, en contacto directo con el movimiento, se vieron influidos por este en su producción literaria, el resto de los escritores estudiados se hallaban lejos de su poder de difusión. Es por ello que rigurosamente, sus novelas podrían no ser catalogadas como indigenistas inicialmente, pero a tenor de las descripciones que del movimiento literario análogo se han venido realizando, no ya como movimiento sociopolítico, sino como subgénero temático, a la postre la novela indigenista no debería ser considerada regional, sino universal.

De esta manera podemos afirmar la existencia de diferentes focos de la literatura indigenista cuyos orígenes a corto plazo difieren, pero cuyo objetivo se mantiene: la reivindicación social, la cual debe ocurrir necesariamente en una sociedad enfrentada, con explotadores y explotados, circunstancias que hacen posibles novelas con contenido, estructura y características muy similares. Por tanto, si bien el macrouniverso circundante a la sociedad indígena peruana atañe a una nación completa y el correspondiente a la argentina solo se circunscribe a comunidades aisladas, o en el mejor de los casos, a provincias muy alejadas de la capital, la fundamentación de la denuncia es básicamente la misma, a la que añadiremos el agravante en el caso argentino que, como venimos insistiendo, corresponde a la negación, no solo política y metaliterariamente, sino también críticamente.

A este respecto, cabe recordar la definición de la novela Aves sin nido como precursora, antecedente o primera obra indigenista según diversos críticos que ni 
siquiera mencionan a su mentora, Juana Manuela Gorriti, hecho que no pasa desapercibido para René Prieto y Efraín Kristal, quien además señala otros intelectuales que denunciaron la situación del indígena con mucha anterioridad y con mayor detalle que González Prada. Resulta paradójico, cuanto menos, que Gorriti, quien fundase una revista literaria y fuese anfitriona de un conocido salón literario en Lima, ambos círculos con especial foco en el problema indígena, no haya captado la atención de los teóricos más prestigiosos del indigenismo y, en general, haya sido olvidada por la crítica literaria peruana, la misma que encumbró a Clorinda Matto de Turner, quien fue patrocinada precisamente por Juana Manuela Gorriti'. Tampoco se hace mención al drama de Tupac-Amaru (1821) atribuido a Luis Ambrosio Morante, actor argentino, que según Concha Meléndez, representa la primera defensa literaria del indio peruano. Aunque aquí no se discute la exclusividad del origen, se destaca su ausencia en la controversia. Así, Kristal sitúa a El padre Horán como primera novela indigenista (1848); Arribas García a La trinidad del indio o costumbres de interior (1885); Cometta Manzoni, Catherine Saintoul y Luis Alberto Sánchez a Aves sin nido (1889); Evelio Echevarría a WaraWara (1904); y Mariátegui y Escajadillo a Cuentos andinos (1920). Cornejo Polar, aunque no se significa plenamente, incluye a Aves sin nido dentro de sus estudios sobre indigenismo. La crítica, pues, silencia los orígenes argentinos de la corriente literaria.

En la crítica generalizada y de obras no precursoras, es decir, plenamente indigenistas, se extiende este silencio, que, como mucho, se ve alterado por menciones de soslayo. Luis Alberto Sánchez, en uno de los primeros estudios literarios sobre indigenismo, elabora un largo listado de novelas, nombrando, entre los autores argentinos, "La raza sufrida, de Carlos B. Quiroga...; Hasta aqui no más, de Pablo Rojas Paz[...], las novelas de Fausto Burgos, B. González Arrili, alguna de Hugo Wast..." (1953:564). Llama la atención la inclusión de la novela de Quiroga, que a pesar de sus retratos de la vida indígena, no denuncia ninguna

9 "En el caso de la Gorriti, los recuerdos literarios no olvidan ni su relación matrimonial con el general Belzú (sic), luego presidente de Bolivia, ni sus veladas literarias. Sin embargo pocos se acuerdan de su obra literaria propiamente dicha: Palma, quien la conoció bien, se limita a decir de ella que conformaba el grupo de quienes por aquellos años "manejaban con algún brillo la pluma del prosador o del poeta" y que escribieron para La Revista de Lima [no dice que también se expresó encomioso sobre La quena en el mismo texto]. Riva Agüero, después de pedir disculpas por su franqueza declara que "como escritora me parece detestable. Son sus obras las tediosas, afectadas y tontas que produjo la escuela romántica [...]. Si algún recuerdo merece La quena es porque por la fecha de su publicación (1846) resulta ser una de las primeras obras francamente románticas que se escribieron en el Perú". Los demás historiadores de la literatura peruana la soslayan” (Alberto Varillas en Glave 1996). 
explotación ${ }^{10}$, así como la de Hugo Wast, conocido antisemita, y las obras de González Arrili, cuyos referentes indígenas solo logran entonar un discurso incaísta. El resto de autores nombrados, como observamos, son confinados a un segundo plano, aunque incluye la totalidad de la obra de Fausto Burgos sin detenerse, al contrario de lo que hizo con muchos escritores peruanos, bolivianos, mexicanos, colombianos, guatemaltecos y ecuatorianos a lo largo de veinte páginas.

Ya en la academia argentina, escasos críticos se atreven a identificar el vocablo "indigenismo" con ciertas obras o autores con estas características. Es más, resulta complicado encontrar estudios sobre dichas obras o escritores a nivel nacional y cuando se hallan, estos son abordados en el específico y muy especializado campo de la literatura regional, cuyos espacios de difusión se encuentran diseminados por las diferentes provincias argentinas, alejadas de la capital y por tanto, del canon.

Sin embargo, ha sido en el territorio de la literatura regional donde la crítica revaloriza y dota de prestigio a las obras olvidadas, y aunque la perspectiva rara vez sea desde la teoría indigenista, secundariamente se hallan ecos de su relación con esta, aunque a menudo se suele caer en catalogaciones más generales, como "literatura de denuncia social", "literatura sobre indígenas", "literatura criollista", "literatura de inspiración folklórica" o términos similares.

El estudio más elocuente, por completo, lo firma Alicia Poderti en su tesis doctoral La narrativa del Noroeste argentino, que posteriormente fue editado. Además de citar el cuento de Gorriti mencionado, incluye también La quena dentro de la narrativa de índole indigenista y sitúa a Manuel J. Castilla en el espacio del indigenismo de vanguardia. No obstante, aunque revisa la obra de Fausto Burgos y Pablo Rojas Paz dentro de la misma corriente nativista postromántica, extraña su desvinculación con el indigenismo.

Beatriz Sarlo, por su parte, denuncia el olvido al que han sido relegadas ciertas obras del regionalismo y denomina "indigenismo exterior y quechuismo" a la corriente denunciatoria que sigue la misma línea inaugurada por Rojas, enmarcada dentro de la tónica nativista sin aportes significativos propios del indigenismo ${ }^{11}$.

${ }^{10}$ “Sin bien La raza sufrida es una novela de proyecciones sociales, en ella no grita la protesta iracunda, ni siquiera implícita, que surge de las narraciones trágicas... del guatemalteco Miguel Ángel Asturias, del ecuatoriano Jorge Icaza, del peruano Ciro Alegría, del argentino Alfredo Varela, del paraguayo Augusto Roa Bastos y de la obra más reciente, Todas las sangres, de José María Arguedas, también peruano. La raza sufrida no denuncia una servidumbre racial y de clase; cuenta y pinta, sencillamente, con amor y con admiración, y en tal aspecto tiene más analogía con Don Segundo Sombra, novela de la pampa argentina, que con algunos de aquellos conmovedores alegatos" (Quiroga 1968:7).

11 "El indigenismo exterior y el quechuismo no pueden ser sino los correlatos literarios de estos temas ideológicos; abundan las narraciones cuyo eje es la brutalidad, la violencia, el primitivismo indígenas enfrentados complementariamente con la exaltación de sus cualidades abstractas: destreza, silencio taciturno y viril, frescura romántica de ciertos 
Sarlo no añade ni autores ni obras específicas, pero nombra a Juan Carlos Dávalos y Fausto Burgos como escritores regionales con óptica paternalista sobre las desigualdades sociales.

Sorprendentemente, uno de los primeros estudios sobre indigenismo (1939) sitúa la poesía argentina como la más prolífica de América en términos de indigenismo literario, y justifica esta presencia debido a que "se cultiva en los países indoamericanos que tienen mayor porcentaje de raza blanca". Su autora, Aída Cometta Manzoni, denomina "indigenismo revolucionario y beligerante" al practicado en "los países indoamericanos donde el indio es una realidad, allí donde constituye un problema que urge resolver, donde su miseria, su angustia y la espantosa situación que soporta lo colocan al margen de la sociedad civilizada". Sin embargo, en una obra posterior (1960) dedicada a la novela, la crítica argentina invierte su conclusión anterior, aduciendo que la literatura indigenista se produce en los países con mayor porcentaje indígena ${ }^{12}$, y aunque analiza la producción en varios países andinos, no incluye ni una sola obra ni autor argentinos.

\section{La narrativa indigenista argentina como producción regional}

Durante el periodo de eclosión del indigenismo en los países más paradigmáticos, que coincidió con el movimiento social indigenista peruano, es decir, en la década de 1920, en Argentina ya comenzaban a publicarse novelas de índole denunciatoria sobre el indígena. Sin embargo, el dominio intelectual de Buenos Aires imposibilitaba de alguna manera el reconocimiento de lo que poco a poco fue llamándose "literatura regional", que solía llevar asociados tintes peyorativos, y solo cuando un autor del interior triunfaba universalmente, su obra se elevaba a "literatura nacional", como es el caso de Lugones o Sarmiento ${ }^{13}$. Por supuesto, el desprecio por parte de sectores bonaerenses de la literatura regional

amores juveniles. Si en escritores como Dávalos esto configura sólo la zona menos apreciable de su literatura, complementada con relatos memorables como "El viento blanco", en otros narradores, el indigenismo, con el pretexto de la defensa, se limita al registro de las supersticiones, la toponimia, la botánica y las leyendas: la línea inaugurada por Rojas termina en los Cuentos de la montaña de Alberto Córdoba, publicados en 1941" (Zanetti 1986:34).

12 "En los países de gran porcentaje Indígena, donde el indio constituye la clase desheredada y explotada, donde su drama adquiere mayor intensidad, se observa en la literatura, una corriente indigenista que representa el sentido de justicia social de esos pueblos" (Cometta Manzoni 1960:12).

13 "Cuando la obra regional es valiosa, cuando logra difusión en el país y en el mundo, parece que deja de ser regional para convertirse en nacional: tal es el caso de los Romances del Río Seco, de Lugones o Recuerdos de provincia, de Sarmiento. Si el escritor del interior se traslada a Buenos Aires y desde allí logra imponerse, [...] deja también de ser regional para convertirse en nacional" (Videla de Rivero 1984:15). 
abrigaba (y abriga) bases razonables, pues, según Videla de Rivero, se le acusaba de "caer en el folklorismo", "establecer un culto a los linajes", "sacralizar el paisaje" y "cultivar el cebo del costumbrismo" (1984:22), aunque de acuerdo a la misma autora, las refutaciones carecían de fundamento si la obra literaria tenía calidad artística.

Según Pedro Luis Barcia, el adjetivo "regional" puede tener hasta tres niveles semánticos, a saber, meiorativo, peyorativo y descriptivo. "Las dos primeras acepciones, la meiorativa y la peiorativa, opuestas, coinciden en que aluden a la misma realidad: la literatura regionalista. La tercera acepción, la objetiva o descriptiva, corresponde a la literatura regional" (Videla de Rivero y Castellino 2004:41). Esta última tiene una dimensión universal, pues aunque su base topográfica es localizada, es integradora, mientras que la literatura regionalista estaría muy identificada con el pasquín costumbrista, sentimentaloide, exhibicionista y excesivamente enciclopédico. Ambas clasificaciones pueden contener literatura folclórica, pero no necesariamente lo contrario. Afirma Barcia que la "literatura regional es el nombre verdadero de la literatura", pues, apelando a Unamuno, "la infinitud y la eternidad hemos de ir a buscarlas en el seno de nuestro recinto y de nuestra hora, de nuestro país y de nuestra época" (Videla de Rivero y Castellino 2004:44).

En la misma línea de diferenciaciones, Silvia Castillo propone otra nomenclatura, la corriente nativista y la auténtica. La primera de ellas estaría relacionada con la interpretación interesada de los aspectos folklóricos en una determinada región para reformularlos de acuerdo a la producción institucionalizada, mientras que la proyección auténtica establece una relación pragmática entre la producción literaria, el referente y el lector (Mata de López y Palermo 2000:138). A la proyección nativista corresponderían las obras regionalistas de finales del siglo XIX que aspiraban a construir la nación argentina desde una perspectiva regional, como pretendieron Joaquín V. González o Martiniano Leguizamón e incluso más recientemente, la revista Nativa.

Estas diferenciaciones entre literatura canónica y pseudoliteratura se plasmarían de manera pragmática en 1944 en el manifiesto del grupo "La Carpa", cuyos miembros se desvinculaban de cualquier traza de nativismo o "falso folklorismo", aunque proclamaban su amor hacia el terruño con una dimensión universalista. Esta declaración de intenciones suponía, desde luego, un ataque hacia ciertos autores de la región noroéstica con rasgos claramente nativistas, como Barcia señalaba precisamente a la producción "regionalista".

Sostiene Videla de Rivero que la literatura regional no logra alcanzar proyección nacional debido al centralismo exacerbado imperante en Argentina. Al no seguir los consejos de Manuel Gálvez, quien proponía que la verdadera argentinidad se conseguiría al retornar al interior, Buenos Aires no lograría universalizar la originalidad de su literatura, marcadamente europeísta. Del mismo modo opinaba 
Canal Feijóo, quien vinculaba la autenticidad cultural al retorno a las raíces mediterráneas.

Desde Buenos Aires se apuntó al vacío que el interior no reflejaba en la cultura nacional, y así, en 1925, la revista Valoraciones y en 1928, Nosotros plantean la necesidad de otra representación de la argentinidad en la literatura ${ }^{14}$, llamando a los autores del interior, aunque a esas alturas, la producción literaria en las regiones era intensa, como lo demuestran los grupos culturales que se formaron y cuyos miembros fueron destacados escritores. En particular, en Santiago del Estero, Bernardo Canal Feijóo promovió, en 1925, la creación de "La Brasa", que aglutinó "a los que creen que la cultura es una justificación de la vida". De diversas partes del Noroeste, ciertos intelectuales que no se dejaron arrastrar por las corrientes vanguardistas bonaerenses, se identificaron con la llamada Generación del '25, entre los que destacan Canal Feijóo, Luis Franco o Samuel Glusberg ${ }^{15}$. En Mendoza, el grupo "Megáfono" se distanciaba del vanguardismo porteño para adherirse al chileno, más próximo geográficamente, y del que formaron parte Fausto Burgos, Alfredo Bufano o Miguel Martos. En general, los escritores más relevantes solían publicar en revistas o periódicos bonaerenses con cierta frecuencia, por lo que no eran desconocidos para el sector intelectual capitalino. Según Castellino, 1928 constituyó el año del despertar para la literatura mendocina, pues se publicaron Cara de tigre, de Fausto Burgos y Cuentos andinos, de Miguel Martos, novelas que inician la narrativa de inspiración folklórica en la región (Castellino 1989:36), aunque Arturo Roig adelanta esta fecha hasta 1925, con la

14 "Del interior del país es donde ha de salir el aliento vital que justificará algún día la existencia de una República Argentina digna de su autonomía en el mundo, no ya por la sola voluntad de sus creadores, sino también por la identificación de sus habitantes con el espíritu de la tierra que trabajan" (Valoraciones, número 6, junio 1925).

"En nuestra cultura falta la voz del interior. La necesitamos. Muchos de nuestros defectos colectivos son los de Buenos Aires, que ha crecido demasiado de prisa, un Buenos Aires hirviente de premura y avideces. A los provincianos corresponde dar una nota de reposo noble, de vida más equilibrada, donde los afanes del espíritu sean fines en sí mismos y no caminos por los que se llega de todas partes cuando se sabe dar hábiles y oportunos rodeos" (Nosotros, número 232, septiembre 1928).

15 “Comienza su actuación un grupo de escritores que, según Luis E. Soto, pertenece a la "generación del '25", y constituye una columna cuyos miembros no tuvieron pretensiones de vincularse con aquellas dos direcciones, reconocidas por la polémica del momento como "Florida y Boedo". No se sentían adversarios de "martinfierristas" o "boedistas" y tampoco tenían órganos oficiales de difusión. Sus miembros no se expresaron a través de manifiestos pero aprovecharon las páginas de Sur, Crítica o La Nación y eligieron el periódico La Vida Literaria -publicado entre 1928 y 1932-, para escribir las colaboraciones que permiten reconstruir el perfil del grupo" (Poderti 2000:124). 
publicación de Poemas de Cuyo, de Alfredo Bufano, que significó la entrada del vanguardismo en la región por medio del sencillismo (1966:49).

Además, durante los años que nos ocupan, muchos autores regionales eligieron la revista La vida literaria, ajena a los enfrentamientos Boedo-Florida, y preocupada por temas exclusivamente literarios, sin que estos atañesen a la política o el vanguardismo. Casualmente o no, su director, Samuel Glusberg fue el principal responsable de la introducción del pensamiento de Mariátegui en Argentina, al colaborar este asiduamente en la revista, y facilitarle el director su asentamiento en Buenos Aires que finalmente truncó su repentina muerte en $1930^{16}$.

El pensamiento de Mariátegui no sería el único contacto que tuviese la cultura argentina con el indigenismo peruano. En 1923, Luis Valcárcel organizó un festival de arte incaico en Argentina, facilitado por Roberto Levillier, entonces embajador en Perú, quien asumió los gastos de esta Misión Peruana de Arte Incaico. El teatro Colón acogió las representaciones indígenas, que incluían una escena del Ollantay, y que se repitieron por un mes, cosechando un gran éxito ${ }^{17}$. Pero estos contactos culturales entre Buenos Aires y Cuzco no se limitaron a estas representaciones. La asociación Cuzco-Argentina se vio favorecida, principalmente, y según diversas fuentes, a la intervención de Fausto Burgos. El escritor tucumano visitó Cuzco en 1928, donde conoció personalmente a Luis Valcárcel, quedó impresionado por la campaña indigenista llevada a cabo por este y otros intelectuales y quiso importarla hacia Argentina (Valcárcel 1981:223). Fausto Burgos medió para que tanto Luis Valcárcel como José Uriel García colaborasen, desde finales de la década de los 20 en el suplemento dominical de La Prensa, medio en el que también comenzó a escribir José María Arguedas a partir de 1940, también por recomendación del tucumano. Casi todas estas colaboraciones venían acompañadas por magníficas fotografías de Martín Chambi, adalid de la fotografía indigenista en Perú. Buenos Aires suponía para los indigenistas un medio más propicio que Lima para exponer sus pretensiones, no solo por la distancia (se tardaba menos en llegar a la capital argentina que a la peruana desde Cuzco) sino también por el antilimeñismo que se percibía en ciertos sectores cuzqueños, así como la expansión editorial de Buenos Aires hacia Europa ${ }^{18}$.

${ }^{16}$ Ver Tarcus, H., et al. (2002). Mariátegui en la Argentina: o las políticas culturales de Samuel Glusberg. Ciudad de Buenos Aires, Ediciones El Cielo por Asalto.

17 "La noche del estreno fue impresionante ver el gran Teatro Colón lleno en todas sus localidades, inclusive el palco presidencial, donde podíamos distinguir la figura del Presidente de la República, Marcelo T. de Alvear. Asistieron también algunos Ministros de Estado y distinguidos representantes de la sociedad porteña. La presentación comenzó con el Himno al Sol, que fue recibido con entusiastas aplausos" (Valcárcel 1981:220).

18 "Es este carácter cosmopolita de los periódicos argentinos el que facilitaba no solamente la inclusión de discursos indigenistas -que podrían parecer exóticos- sino que aseguraba su repercusión en una red europea y continental más vasta. En definitiva 
Como no podía ser de otra manera, esta relación también se vio reflejada en el interior, por medio de revistas con espíritu americanista, en donde no solo colaboraban autores indigenistas peruanos, sino argentinos que reivindicaban su esencia hispanoamericana. Entre ellas, a pesar de su corta trayectoria, destacan Sol y nieve (1922), Tucumán ilustrado (1923), Aconcagua (1927-1930), Áurea (19271928), El Carcaj (1928-1929), Inti Raymi (1927), Nam (1933-1934), Transición (1935), Ayacucho (1937-1944), Itinerario de América (1938-1941) y PAN (1935$1940)^{19}$.

Otra manifestación indigenista que recibió los preceptos vanguardistas y en la que participaron diversos escritores argentinos fue el Boletín Titikaka (1926-1930). Fundado por Gamaliel Churata en Puno, el Boletín difundía los escritos del grupo Orkopata $^{20} \mathrm{y}$ de diferentes personalidades indigenistas, como Luis Valcárcel, José Carlos Mariátegui o Haya de la Torre. Por medio del canje, Churata conseguía, por un lado, promocionar a su grupo fuera de las fronteras peruanas, y al mismo tiempo, acercar a la fronteriza e inaccesible ciudad de Puno las últimas manifestaciones literarias del continente. De esta manera se explica la presencia de Borges, Girondo o Güiraldes en el Boletín. Pero también la inclusión de poemas de Manuel Ugarte o la participación de Fausto Burgos en las reuniones del grupo Orkopata (Graziano 2014). Posteriormente, Manuel J. Castilla estaría en contacto con Churata en Bolivia, lo que le permitió de primera mano conocer la producción indigenista y que sin duda influiría en su obra poética y narrativa (Poderti 2000:130).

El movimiento indigenista, por tanto, no era desconocido para la intelectualidad argentina, y más de un escritor se vio salpicado por su afán denunciatorio y de

aseguraba un valor agregado de prestigio internacional para los escritos de la intelectualidad del sur del Perú" (Kuon Arce et al. 2008:188).

19 "En estas revistas solían aparecer artículos de la actualidad coyuntural o de un alcance menos efímero que apuntaban a consolidar las relaciones entre el Perú y Argentina de una forma genérica. Es cierto que los autores peruanos que con más frecuencia aparecían suscribiendo textos eran fundamentalmente aquellos vinculados al campo de la política y las ideas como José Carlos Mariátegui, Víctor Raúl Haya de la Torre y Luis Alberto Sánchez, pero ello no obvia la directa relación con sus posturas y la vinculación a los problemas sociales y culturales del mundo andino...Este panorama complementa por lo tanto, en un círculo más militante o articulado ideológicamente la presencia singular del pensamiento peruano de la vanguardia y de la tradición en tiempos de esta enriquecedora aproximación cultural" (Kuon Arce et al. 2008:224-225).

20 "En Orkopata, un pueblo aledaño de Puno, [Gamaliel Churata] presidía un cenáculo o tertulia, una especie de "seminario al aire libre" en cuyas reuniones (llamadas "pascanas nocturas") se comentaban novedades literarias y políticas. Formaban parte del llamado "Grupo Orkopata", jóvenes escritores puneños que luego alcanzarían cierta fama nacional y, en algunos casos, más allá de la frontera peruana: los poetas Alejandro Peralta, Emilio Armaza y Luis de Rodrigo, los prosistas Danta Nava y "Mateo Jaika" y otras figuras como Benjamín Camacho y el dramaturgo vernáculo Inocencio Mamani” (Wise 1984:94). 
visibilidad. El mismo Ricardo Rojas, quien fue investido Doctor Honoris Causa por la Universidad de Cuzco, fue quizá el mayor divulgador del indigenismo en Argentina. Probablemente no fue del todo consciente de ello pues la principal tarea de este movimiento consistía básicamente en lo que él mismo había iniciado a principios de siglo con sus teorías integradoras, que culminarían en 1924 con la publicación de Eurindia. Esta obra, que pretendía rescatar la tradición indígena y española en la identidad argentina, revalorizaba las virtudes de una raza que sus contemporáneos más ilustres pretendían aniquilar.

\section{Obras indigenistas en Argentina}

Como adelantábamos al comienzo, fue sin duda Juana Manuela Gorriti la precursora de la narrativa indigenista en Argentina con su cuento "Si haces mal no esperes bien". El cuento, dividido en cuatro capítulos, fue publicado en 1861 en $L a$ Revista de Lima y posteriormente en La Revista de Buenos Aires. En él se retratan las consecuencias de la opresión hacia el sector indígena de la población, centrándose en un drama romántico de nefastas consecuencias. La autora focaliza el abuso de una sociedad feudal corrupta en la "trinidad embrutecedora" que González Prada denunciaría treinta años después: el cura, el juez y el soldado, y lejos de concentrar su historia en la elitista descendencia inca, lo hace con los anónimos indígenas sometidos durante siglos por el europeo y el criollo, y a los que cede su voz para denunciar la tiranía y el abuso.

Ya en el siglo XX, el santafecino Alcides Greca dirigió una de las primeras manifestaciones artísticas indigenistas del continente con su película El último malón, de 1917, para la cual se basó en la sublevación mocoví que tuvo lugar en el Chaco en 1904 y donde se masacró a los indígenas que no lograron huir. En la película, la imagen proyectada del mocoví es ambigua, ya que, aunque por un lado se retratan las virtudes de su vida y costumbres, por otro lado se ofrece una visión estereotipada, cuando estos se enfrentan contra el colono ${ }^{21}$. Claramente, el mensaje de la película-documental es denunciatorio, pero no ofrece solución más que la romántica huida bucólica que no resuelve los conflictos interétnicos ni el progreso del indígena, a quien confina a su pasado selvático.

La novela posterior que publicó Greca en 1927, Viento norte, está basada también en esta sublevación y en la conocida matanza de Napalpí, donde en 1924 se disparó indiscriminadamente contra más de 400 indígenas después de una huelga declarada por las condiciones de semiesclavitud en las que trabajaban.

\footnotetext{
21 “Aunque en general los indígenas parecen peones, en la escena del ritual en las que los indígenas se convocan para planear la resistencia se produce un retroceso y se los presenta con vinchas de plumas y pieles, y aún provistos con arco y flecha, tal como aparece el protagonista al recordar la época que antecede a la reservación y al período en que escapa y vive en el Chaco" (2014).
} 
El panorama dibujado por Greca reviste una polarización extrema en la que el único término medio existente reside en el protagonista, que en ocasiones, adopta tintes mesiánicos. La trama de la novela, además, solo se focaliza en la vida y costumbres occidentales y cuando ambas se entrecruzan, la comunidad indígena se circunscribe a un ámbito selvático. Solo la compasión y el soborno actúan como mediadores entre ambos mundos, que parecen irreconciliables. Sin embargo, Greca exhibe cierto paternalismo hacia los indígenas, ya que en varios puntos de la novela se precisa la intervención del blanco redentor para su supervivencia, y no solo en casos de convivencia interétnica, sino también en la superación de sus propios problemas cotidianos y tradicionales.

Alcides Greca representa de manera soberbia la imagen social de la Argentina de principios de siglo, e introduce un indigenismo alejado de los cánones del andino. El argentino denuncia y condena los abusos del blanco sobre el indígena, pero además, también recrimina su exterminio, práctica avalada por la sociedad de la época si nos atenemos a los diarios ${ }^{22}$, donde cualquier levantamiento indígena era considerado un malón y su derrota era aplaudida.

Una novela anterior e insertada dentro de la trilogía Tres novelas jujeñas la firma quien fuera primer gobernador del Partido Radical en la provincia de Jujuy, Horacio Carrillo (1887-1955), entre 1918 y 1921. Con un hilo argumental débilmente estructurado, La mano que implora rebasa el mero pasquín político por cuanto su adscripción a la narrativa indigenista. A pesar de las estas deficiencias literarias, existen, a lo largo de la novela, y en el argumento central de la misma, rasgos precisos del indigenismo ortodoxo, como define Escajadillo a la novela anterior a la neoindigenista, y que incluye, además de la mencionada denuncia social, la ruptura con el pasado y el acercamiento al referente.

La originalidad de la novela reside en dos cuestiones que se alimentan entre sí. En primer lugar, la denuncia de las condiciones de extrema pobreza que sufre el puneño, tipo humano característico del noroeste argentino, lo cual le servirá a Carrillo para exponer su proyecto político. En La mano que implora, asistimos a dos acontecimientos de importancia en relación a las injusticias sociales cometidas sobre el indígena argentino. En primer lugar, la llegada masiva de puneños para trabajar en los ingenios del azúcar retrata las condiciones de miseria que sufren en

22 "A través de la prensa se manifiestan las ideas positivistas imperantes en términos de 'civilización o barbarie', que suponen una legitimación ideológica hacia las concepciones que "demonizan" a los pueblos indígenas, justificando así el accionar del Estado. Los distintos diarios se posicionan frente a las medidas de represión planteadas, que pueden resumirse de esta manera: por un lado, impedir el desarrollo de la cultura "salvaje" para que todos estos individuos pudiesen ser convenientemente incorporados como mano de obra para el desarrollo productivo del país; por el otro, exterminar definitivamente a estos pobladores considerados un obstáculo al avance de la civilización, "liberando" sus territorios para la llegada de inmigrantes europeos" (Greca 2009). 
sus lugares de origen, en la Puna. En segundo lugar, esta migración corresponde, en parte, a la llamada de los hacendados ante la falta de mano de obra tras la retirada de los indios tobas hacia el Chaco, su provincia originaria. Los indios del Chaco fueron, durante años, obligados mediante amenazas de represión a trabajar en condiciones de semiesclavitud en los ingenios azucareros de las provincias vecinas hasta que los propios gobernantes de la provincia norteña, ante la demanda de trabajo en sus propios campos de algodón, prohibieron su movilización.

Aunque esta novela se situaría en un escalón intermedio entre Gorriti y Greca, Carrillo sí expone los dos principales problemas de los indígenas de Jujuy, enumera sus sufrimientos, justifica sus requerimientos, denuncia algunas de sus condiciones de explotación, pero no relata con precisión las razones de estas demandas y la solución que ofrece responde a sus propios intereses. En resumen, se trata de una historia creada para persuadir a una población preocupada por el clima de tensión social y escasamente informada.

Pablo Rojas Paz, conocido principalmente por haber cofundado la revista Proa, sin embargo es autor de una vastísima producción literaria, mayoritariamente con rasgos regionales, pues el autor era originario de Tucumán. Su novela Hasta aquí, no más, de 1936, es una de las pocas obras argentinas nombradas en la crítica indigenista.

No obstante, varias de sus novelas revisten rasgos denunciatorios, y entre ellas destaca Hombres grises montañas azules, de 1930. En ella, el ambiente rural de una sociedad heterogénea, pero dominada por blancos, sirve de escaparate para retratar la estratificación racial, avalada por la susodicha "trinidad embrutecedora", que además permite la humillación continuada y la imposibilidad de ascenso social de los indígenas, que viven sometidos desde su nacimiento. La narración se centra en un adolescente indígena cuyo destino depende de la voluntad de sus patrones a pesar de sus deseos, de su amor por la vida y su ignorancia sobre la vida urbana. El resultado es una hermosa descripción de la sierra de Tucumán cuyos habitantes pelean por sobrevivir en una sociedad donde todo ya está repartido y sin sentimentalismos, aborda la falta de esperanza de una infancia fugaz y mísera.

Hasta aquí, no más acomete los mismos temas pero desde una perspectiva mucho menos embellecedora y desde los ojos de un mestizo que se gana el favor de su patrón. A través de él conoceremos los entresijos de la alta sociedad tucumana y su pésimo trato a los indígenas. Los ricos hacendados roban descaradamente la tierra a aquellos mediante escaramuzas y amenazas mientras asesinan indiscriminadamente a los que se atrevan a levantarse en contra del patrón, quien cuenta con el beneplácito de las autoridades policiales y jurídicas.

A pesar de su pasado martinfierrista, Rojas Paz no duda en escribir novelas sociales que describen la dura realidad de sus compatriotas tucumanos, cosificados y ninguneados tanto por las altas esferas como por el resto de habitantes. Es cierto que no ofrece soluciones pragmáticas, pero sus narraciones reivindican los gritos desgarrados de las voces olvidadas. 
Pero indudablemente, la obra que descolla en esta época es El salar, de Fausto Burgos, publicada en 1935. Se trata de la novela argentina indigenista por excelencia y a pesar de su evidente calidad y de que además, presenta claros rasgos neoindigenistas, adelantándose por cierto a El mundo es ancho y ajeno y Yawar fiesta en seis años, Fausto Burgos permanece en un incomprensible olvido, que solo últimamente está despertando, tras la publicación de la obra por la Biblioteca Nacional Argentina con motivo del Bicentenario de la Independencia, aunque, como no podía ser de otra manera, en la colección de "Los raros".

El salar es la historia de una venganza por una serie de afrentas urdidas antes y durante la duración de la novela por parte del poderoso hombre blanco frente al resignado y mísero indígena. El protagonista, un porteño de clase media, sueña con el hijo que tuvo con una indígena de Jujuy ocho años atrás y parte hacia allá con el capricho de recuperarlo. La indígena tiene otros vástagos con su marido, un anciano colla, quienes viven cerca de un salar de donde sacan su sustento. La sal cortada, en durísimas condiciones, es comprada por los comerciantes de la zona, quienes imponen un precio escandalosamente bajo. El porteño, para mayor humillación de la familia indígena, los acompaña a vivir y trabajar durante unas semanas, durante las cuales reclama a su hijo, quien lo ignora sistemáticamente, a pesar de las promesas económicas del blanco. Al final, el anciano colla abandona a su familia y la mujer, Rosario, enloquece, abandonando al porteño en el salar ante el riesgo de ceguera y surumpio.

El protagonista, don Carlos, es capaz de compadecer a los indígenas e incluso de odiar a sus explotadores. Sin embargo, a pesar de esa confraternización con el universo indígena y su capacidad de denuncia frente a los demás y a sí mismo, este los somete a una humillación incluso peor que los comerciantes, ya que es capaz de romper la armonía - mísera armonía - que los explotadores no han conseguido a pesar del injusto trato monetario.

Efectivamente, quienes no tienen nada que perder demuestran mayor entidad moral, ya que mientras las aspiraciones vitales de los blancos se centran en pautas sociales que los alejan de la realidad natural, los indígenas se agarran a la tierra y la familia. Estos aceptan su destino con humildad y resignación. Consienten toda clase de tropelías hacia ellos, las violaciones, las humillaciones, la explotación indiscriminada, pero no toleran el quebranto de sus tradiciones.

El acto final de Javier Chutuska, de abandonar a su familia, responde a un castigo infringido a Rosario, quien no ha sabido detener a don Carlos. La falta de rigor de la indígena puede extenderse a toda la raza, quienes no han podido o sabido frenar el atropello blanco, que continuará mientras no se levanten contra el invasor. La lección aprendida en El salar conmina a las corrientes indigenistas a dejar que sean ellos mismos, sin la intervención del blanco, quienes lideren su liberación, como anticipó González Prada, allá en 1904, en Nuestros indios.

El salar pues, no es la narración de una explotación aislada. La trama sirve de excusa para describir las durísimas condiciones de vida de toda una comunidad que 
es sistemáticamente oprimida por su entorno físico y humano y la indiferencia de la mal llamada civilización quienes, como mucho, la compadecen, aunque a un nivel animalizado. Los indígenas solo pueden refugiarse en su misticismo para soliviantar su miseria, a la que no se enfrentan.

Fausto Burgos firmó también otras novelas de corte indigenista, como La cabeza del Huiracocha y la colección de cuentos Cachisumpi, que por la brevedad de este artículo no serán analizados aquí, así como las obras de otros autores como César Carrizo. Todas ellas serán objeto de estudio en un trabajo posterior más amplio.

En este, sin embargo, se ha pretendido poner de manifiesto la multitud de ejemplos literarios indigenistas que existen en la narrativa argentina y que por la misma razón de su existencia, nunca han sido considerados por la crítica. Efectivamente, el indigenismo argentino difiere del peruano en sus demandas. Las políticas de invisibilización del indígena argentino por parte de las autoridades desde mediados del siglo XIX funcionaron hasta alcanzar cotas artísticas, y es por eso que los escritores a los que nos hemos referido cumplieron una doble misión: formar parte del silencio que sus propios referentes denunciaron.

\section{BIBLIOGRAFÍA}

BuRgos, Fausto.

2010 El salar. Buenos Aires: Biblioteca Nacional.

CARRILLO, Horacio.

1943 Tres novelas jujeñas. Jujuy [Argentine]: Buttazzoni. CASTELLinO, Marta.

1989 FaustoBurgos y la narrativa de inspiración folklórica mendocina (en el marco de la generación del '25". La periodización de la literatura argentina: problemas, criterios, autores, textos. Actas del IV Congreso Nacional de Literatura Argentina.

CometTa MANZONI, Aída.

1939 El indio en la poesía de América española. Buenos Aires: J. Torres.

1960 El indio en la novela de América. Vol. 14. Buenos Aires: Editorial Futuro.

CORNEJO POLAR, Antonio.

1980 Literatura y sociedad en el Perú: la novela indigenista. Vol. 1. Lima: Lasontay.

ECHEVARRÍA, Evelio.

"La novela indigenista hispanoamericana: Definición y bibliografia", Revista Interamericana de Bibliografia/InterAmerican Review of Bibliography, vol. 35, no 3, pp. 289-296. 
ESCAJADILLO, Tomás G.

"El indigenismo narrativo peruano", Philologia hispalensis, vol. 4, $\mathrm{n}^{\mathrm{o}} 1$, pp. 117-136.

1994 La narrativa indigenista peruana. Lima: Amaru Editores.

GLAVE, Luis Miguel.

"Letras de mujer. Juana Manuela Gorriti y la imaginación nacional andina, siglo XIX", Ideele, no 86, pp. 119-137.

GONZÁLEZ ECHEVARRÍA, Roberto y Enrique PUPO-WALKER.

2008 The Cambridge history of Latin American literature.

GONZÁLEZ PRADA, Manuel.

1978 Nuestros indios. México: Unión de Universidades de América Latina: Universidad Nacional Autónoma de México, Coordinación de Humanidades, Centro de Estudios Latinoamericanos, Facultad de Filosofía y Letras.

GORRITI, Juana Manuela.

1865 Sueños y realidades. Obras completas de la señora doña Juana Manuela Gorriti. Argentina.

GRAZIANO, Silvia.

2014 Exilios, vanguardias y regionalismo: presencia de escritores y artistas plásticos argentinos en el Boletín Titikaka. Quinto congreso internacional CELEHIS de literatura.

GRECA, Alcides.

1917 El último malón. Película.

1938 Viento norte. Buenos Aires: Claridad.

GRECA, Verónica.

"Un proceso de rebelión indígena: los mocovíes de San Javier en 1904," Avá: Revista de Antropología, no 15, pp. 333-349.

GULLÓN, Ricardo.

1990 Direcciones del modernismo. Madrid: Alianza Editorial.

KRISTAL, Efraín.

1991 Una visión urbana de los Andes : génesis y desarrollo del indigenismo en el Perú: 1848-1930. Lima: Instituto de Apoyo Agrario.

KUON ARCE, Elizabeth et al.

2008 Cuzco-Buenos Aires Ruta de Intelectualidad Americana (19001950). Lima: Universidad de San Martín de Porres.

MATA DE LÓPEZ, Sara y Zulma PALERMO.

2000 Travesía discursiva: representaciones identitarias en Salta, siglos XVIII-XXI. Rosario: Prohistoria Ediciones.

MELÉNDEZ, Concha.

1961 La novela indianista en Hispanoamérica, 1832-1889. Río Piedras: Ediciones de la Universidad de Puerto Rico. 
Morante, Luis Ambrosio, Jorge Max ROHDE y BIBLIOTECA NACIONAL.

1924 Tupac-Amarú, drama en cinco actos, año de 1821. Buenos Aires: "Coni ".

PODERTI, Alicia.

2000 La narrativa del noroeste argentino: historia socio-cultural. Salta: Editorial MILOR.

PRIETO, Adolfo.

1988 El discurso criollista en la formación de la Argentina moderna. Buenos Aires: Editorial Sudamericana.

Quiroga, Carlos B.

1968 La raza sufrida. Buenos Aires: Editorial Universitaria de Buenos Aires.

RAMA, Ángel.

1982 Transculturación narrativa en América Latina. Madrid: Siglo veintiuno editores, S.A.

RODRÍGUEZ-LUIS, Julio.

"El indigenismo como proyecto literario: Revaloración y nuevas perspectivas", Hispamérica, vol. 19, nº 55, pp. 41-50.

RoIG, Arturo Andrés.

1966 Breve historia intelectual de Mendoza: los coloniales, la ilustración, el neo clasicismo, el romanticismo, los modernos, el positivismo, el espirtiualismo filosófico, el regionalismo literario. Mendoza: Ediciones del Terruño.

ROJAS PAZ, Pablo.

1966 Hasta aquí, no más. Buenos Aires: Editorial J. Alvarez.

1930 Hombres grises, montañas azules. Buenos Aires: M. Gleizer.

ROJAS, Ricardo.

1951 Eurindia; ensayo de estética sobre las culturas americanas. Buenos Aires: Losada.

SÁNCHEZ, Luis Alberto.

1953 Proceso y contenido de la novela hispanoamericana. Madrid: Gredos.

TARCUS, Horacio et al.

2002 Mariátegui en la Argentina: o las politicas culturales de Samuel Glusberg. Ciudad de Buenos Aires: Ediciones El Cielo por Asalto.

TOMPKINS, Cynthia.

"El último malón de Alcides Greca: Repetición y cine de atracciones", Studies in Latin American Popular Culture, vol. 32, $\mathrm{n}^{\mathrm{o}}$ 1, pp. 97-119.

VALCÁRCEL, Luis E.

1981 Memorias. Lima: Instituto de Estudios Peruanos. 
VIDELA DE RIVERO, Gloria.

"Las vertientes regionales de la literatura argentina", Rev.de Lits.Mods, vol. 17, pp. 11-26.

VIDELA DE RIVERO, Gloria y Marta Elena CASTELLINO.

2004 Literatura de las regiones argentinas. Mendoza: Universidad Nacional de Cuyo, Facultad de Filosofíia y Letras, Centro de Estudios de Literatura de Mendoza.

WISE, David.

"Vanguardismo a 3800 metros: El caso del Boletin Titikaka (Puno, 1926-1930)", Revista de Crítica Literaria Latinoamericana, vol. 10, Nn 20, pp. 89-100.

ZANETTI, Susana.

1986 Historia de la literatura argentina. 4 4. Argentina: Centro ed. de América Latina. 